Article

\title{
Innovative Skin Product O/W Emulsions Containing Lignin, Multiwall Carbon Nanotubes and Graphene Oxide Nanoadditives with Enhanced Sun Protection Factor and UV Stability Properties
}

\author{
Nikolaos D. Bikiaris * , Ioanna Koumentakou, Smaro Lykidou and Nikolaos Nikolaidis*
}

check for

updates

Citation: Bikiaris, N.D.;

Koumentakou, I.; Lykidou, S.;

Nikolaidis, N. Innovative Skin

Product O/W Emulsions Containing

Lignin, Multiwall Carbon Nanotubes and Graphene Oxide Nanoadditives with Enhanced Sun Protection Factor and UV Stability Properties. Appl.

Nano 2022, 3, 1-15. https://doi.org/ 10.3390/applnano3010001

Academic Editor: Jose M. Palomo

Received: 13 December 2021

Accepted: 4 January 2022

Published: 11 January 2022

Publisher's Note: MDPI stays neutral with regard to jurisdictional claims in published maps and institutional affiliations.

Copyright: (C) 2022 by the authors. Licensee MDPI, Basel, Switzerland. This article is an open access article distributed under the terms and conditions of the Creative Commons Attribution (CC BY) license (https:// creativecommons.org/licenses/by/ $4.0 /)$.
Laboratory of Chemistry and Technology of Polymers and Dyes, Department of Chemistry, Aristotle University of Thessaloniki, 54124 Thessaloniki, Greece; iwanna.koumentakou@gmail.com (I.K.); slykidou@chem.auth.gr (S.L.)

* Correspondence: nbikiaris@gmail.com (N.D.B.); nfnikola@chem.auth.gr (N.N.)

\begin{abstract}
In the present study, oil-in-water $(\mathrm{O} / \mathrm{W})$ sunscreen emulsions were prepared containing different portions of lignin (LGN), multiwall carbon nanotubes (MWCNTs) and graphene oxide (GO) nanoadditives. The stability in terms of $\mathrm{pH}$ and viscosity of emulsions was thoroughly studied for up to 90 days, exhibiting high stability for all produced $\mathrm{O} / \mathrm{W}$ emulsions. The antioxidant activity of emulsions was also analyzed, presenting excellent antioxidant properties for the emulsion that contains LGN due to its phenolic compounds. Moreover, the emulsions were evaluated for their ultraviolet (UV) radiation protection ability in terms of sun protection factor (SPF) and UV stability. SPF values varied between 6.48 and 21.24 while the emulsion containing $2 \% w / v$ MWCNTs showed the highest SPF index and all samples demonstrated great UV stability. This work hopefully aims to contributing to the research of more organic additives for cosmetic application with various purposes.
\end{abstract}

Keywords: O/W emulsions; kraft lignin; MWCNTS; graphene oxide; nanoadditives; sun protection Factor; UV stability; antioxidant activity

\section{Introduction}

Skin cancer is the most common disease of human skin, with non-melanoma skin cancer (NMSC) alone consisting at least $40 \%$ of new cancer cases and is estimated to upsurge in the coming decades due to aging population [1]. Endogenous factors, such as $\mathrm{UV}$ radiation due to sun exposure is considered a complete carcinogen factor since it is both a mutagen and a non-specific damaging agent and has properties of both an initiator and a promoter of tumor. Specifically, UV is composed of UV-A (320-400 nm), UV-B (290-320 nm), and UV-C (100-290 nm). UV-C radiation is totally absorbed by the earth's ozone layer, however, the UV-A and UV-B radiations reach the earth surface and are accountable for several skin pathologies such as sunburns, photosensitivity, photoaging, phototoxicity, and most importantly skin cancer [2-4]. On the other hand, UV radiation offers some benefits to human health such as the natural synthesis of vitamin D and endorphins in the skin [3].

Sun Protection Factor (SPF) constitutes a significant feature for cosmetic oils, lotions, and emulsions. It is of great importance since the addition of UV protection agents could assistance the preservation of good skin health and the prevention of oxidative stress. SPF value implies the sun protection efficacy of a product, where usually, a higher SPF index corresponds to more effective sun protection. Nevertheless, various complications have been caused by currently commercial sunscreen products such as erythema, edema, and irritation, among others $[2,5]$.

Cosmetic emulsions including sunscreen products can undergo a number of different instabilities such as gravitational separation, creaming, flocculation, coalescence and phase inversion [6]. The increased concern about these effects led to the addition of stabilizer 
agents such as polymer latexes, inorganic particles, silicone particles, silica, lysosomes, clays, carbon nanotubes, and several others [7-10].

Moreover, the current state-of-the-art products commonly use ingredients of either organic and inorganic UV filters, which absorb/scatter or attenuate the sun UV radiation, thus ensuring protection against sun. Organic UV filters are usually consisted of aromatic molecules conjugated with a carbonyl group and can absorb UV light. Inorganic UV filters, such as titanium dioxide $\left(\mathrm{TiO}_{2}\right)$ or zinc oxide $(\mathrm{ZnO})$, can reflect, scatter, and/or absorb UV light [11,12]. However, generation of reactive oxygen species (ROS) by common sunscreen agents such as $\mathrm{TiO}_{2}$ and $\mathrm{ZnO}$ has led researchers to incorporate effective antioxidant agents into sunscreens. Fullerenes (C60) and nanodiamonds (NDs) are potent antioxidants (radical scavengers) and effective UV filters, making them prime candidates as additives [13].

In the current study, we propose the use of kraft lignin (LGN), graphene oxide (GO) nanoadditives and multiwall carbon nanotubes (MWCNTs) as antioxidant and anti-UV additives in sunscreen emulsions. Various nanomaterials have been utilized for the development of cosmetic products-a field so-called nanocosmetic formulations [14]. The incorporation of nanomaterials into products for personal and health care applications continually gains attention in cosmetic industries. According to market analysis done by Woodrow Wilson Project on Emerging Nanotechnology, since 2013 more than sixteen hundred nanotechnology products have been synthesized, 788 of these are for cosmetic use and an additional 40 products are under the sunscreen category. Additionally, it has been mentioned that the amount of nanocosmetic products increased by nearly $516 \%$ between the years 2006-2013 [14,15]. Several commercial cosmetic formulations containing nanomaterials have been produced by leading manufacturing companies such as Christian Dior (Diorskin Extreme Fit), Kara Vita (Eye Tender with bioactives and peptides), L'Oreal (Revitalift Double Lifting with Pro-Retinol A), Purest Colloids (Mesosilver Antifungal Spray with silver nanoparticles), Joyona International Marketing (Nano Gold 24 Hour Cream with gold nanoparticles), Advanced Nanotechnology Limited (Alusion Alumina Powders with Aluminum oxide nanoparticles), etc. [15]. Consequently, the interest of the scientific community has turned to the development of formulations with various nanoparticles to improve their physicochemical and biological properties. Specifically, gold nanoparticles have been contained in emulsions to synthesize anti-aging formulations [14]. Silver nanoparticles are increasingly being used as antimicrobial and preservative agents due to their enhanced stability [16]. Titanium dioxide and zinc oxide nanoparticles have been also utilized as UV filters in sunscreen products [17]. Additionally, several cosmetic products include carbon nanoparticles, particularly graphene-based ones, which are endowed with heat dissipation abilities and improve emulsion stability [18]. Several works have reported carbon nanoparticles in the formulation of cosmetics for coloring hair, eyelashes, or eyebrows $[19,20]$ while nanocomposite graphene $/ \mathrm{TiO}_{2}$ has been employed as catalyst to build an antioxidant cosmetic formulation [21].

Lignin is a phenolic biopolymer, mainly traced in woody plants and most other terrestrial plants. Lignin has been added to several sunscreen emulsions that are available on the market, presenting excellent improvements in UV absorbance. Specifically, it has been reported that sunscreen products containing $2 \mathrm{wt} \%$ LGN can double the SPF index from 15 to 30. LGN consists of three types of phenyl propanoid structures: coniferyl alcohol (G type), sinapyl alcohol (S type) and para-coumaryl alcohol (H type) units (Figure 1a). All structures bonded together predominantly by aryl glycerol ether linkages and other bonds. The precise structure of plant lignin is difficult to define, and nearly all lignin structures that have been reported based on spectroscopic and chemical analysis of extracted lignin or whole-cell NMR analysis [22]. The exposure of ligno-cellulosic fibers to photo-irradiation cause photo-yellowing, turning their color darker [23]. Light-catalyzed photoreactions with lignin chromophores are considered to be the main mechanisms for photo yellowing of lignin, ultimately resulting in the formation of chromophoric bodies such as quinones. Even after exposure to sunlight, lignin's UV blocking potential can be accelerated by this 
phenomenon. However, the dark color of lignin can reduce final product transparency and thus limits its application in the cosmetic industry [24].

Graphene is a two-dimensional array of carbon atoms aligned in a hexagonal network, in the form of mesh. This structure provides its unique properties of friction and wear [25]. Graphene Oxide is the oxidized form of graphene [26], having a 2D structure (Figure 1b) like graphene [27]. The ease of manufacture of graphene oxide nanoadditives as well as its exceptional water dispersibility, deriving from oxygen containing groups, constitute it an attractive material for various uses. Of rising concern is the ability of GO to adsorb at, and stabilize, air-water and oil-water interfaces. Lately, a thorough investigation of the synthesis of $\mathrm{O} / \mathrm{W}$ emulsions, which have been stabilized with GO, has been conducted, while their effects on $\mathrm{pH}$ and viscosity have been also analyzed. In general, the emulsions display remarkable stability when compared to those stabilized by typical molecular surfactants [28]. Also recently some researchers reported the excellent UV radiation protection property of GO nanoadditives [29].

Multi-walled carbon nanotubes consist of smaller diameter single-walled tubes inside larger diameter tubes and may vary from a double-walled nanotube to as many as fifty concentric tubes [30], presenting diameters ranging from $~ 2-100 \mathrm{~nm}$ [31]. MWCNTs structure (Figure 1c) makes them suitable for stabilizing emulsion due to being harder to desorb from the oil-water interface [31]. During the last decade, the extraordinary stability properties of MWCNTs have encouraged researchers to utilize them as stability agents for $\mathrm{O} / \mathrm{W}$ emulsions, exhibiting great results [32-34]. Moreover, many articles in the literature confirm that MWCNTs may act as excellent UV filters $[35,36]$.

Due to the widespread use of carbon nanoparticles in cosmetic and pharmaceutical products, increasing effort has been made to evaluate carbon nanomaterial biosafety. Several works have proven the biocompatibility of carbon nanotubes and graphene nanomaterials [37-39], while it has been reported that MWCNTs stimulate cell growth [40]. However, it has been shown that the toxicity of carbon nanoparticles depends on several different factors such as their shape, their size, their surface morphology, and the content of nanoparticles in the produced formulations [41].

a)

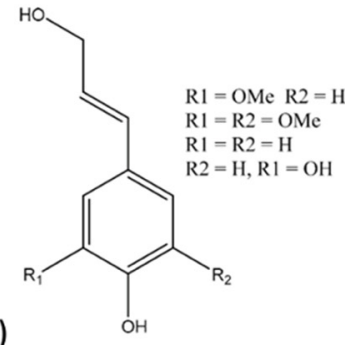

b)

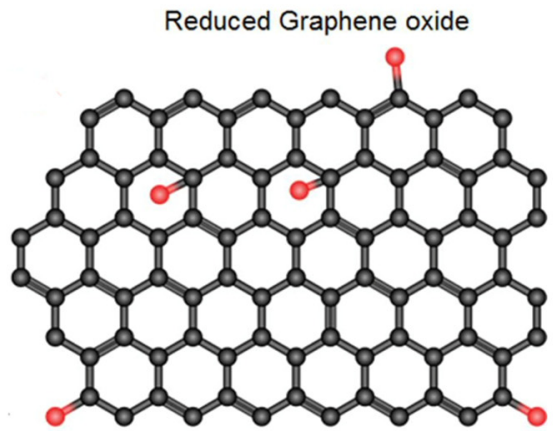

c)

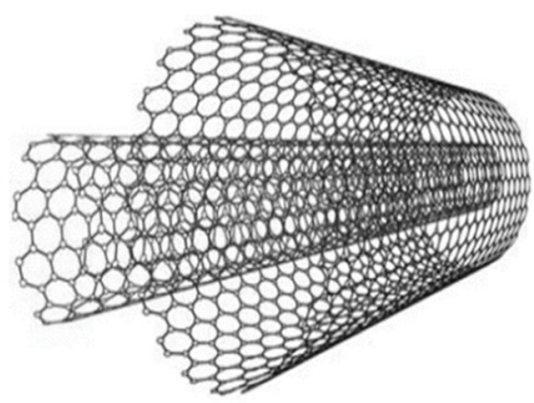

Figure 1. Structures of (a) lignin [22], (b) GO [42] and (c) MWCNTs [43].

The current work is an attempt to fabricate three different model dispersed $\mathrm{O} / \mathrm{W}$ emulsions containing LGN, MWCNTs and GO nanoadditives, and to study their physicochemical properties. More specifically, emphasis was given to study their $\mathrm{pH}$ and viscosity 
stability, antioxidant activity, sun protection and UV stability of the final creams. The results are exhibited in this article.

\section{Materials and Methods}

\subsection{Materials}

Kraft LGN was obtained from Aldrich chemicals (St. Louis, MO, USA). MWCNTs (purity $>95 \mathrm{wt} \%$ ) were purchased from Chengdu Organic Chemicals Co., Ltd. Chinese Academy of Sciences (Chengdu, China). GO were purchased from Strem Chemicals Inc. (7 Mulliken Way, Newburyport, MA, USA). Glycerin, citric acid, xanthan gum, olive oil, cetyl alcohol, cetearyl alcohol, stearic acid, shea butter, beeswax, polysorbate 60, with appropriate purity for cosmetic emulsions, were kindly donated from Novita Group (Thessaloniki, Greece). All other materials used in the present study were of analytical grade.

\subsection{Preparation of the Emulsions}

The preparation of the emulsions was achieved according to $\mathrm{O} / \mathrm{W}$ method as described in previous work [2]. O/W emulsions were prepared containing lignin, GO nanoadditives and MWCNTs in 0.5, 1 and $2 \% w / v$ ratios as exhibited in Figure 2. The list of the utilized ingredients for the preparation of $100 \mathrm{~mL} \mathrm{O} / \mathrm{W}$ emulsions oil are illustrated in the Table 1. The corresponding water and oil phase ingredients were weighed and added separately to glass beakers. The water phase constituted $75 \%$ while the oil phase constituted $25 \%$ of the final emulsion. The two mixtures were heated in parallel, in a water bath at $80{ }^{\circ} \mathrm{C}$, under mechanical stirring until their homogenization. Finally, the oil phase was added drop-by-drop to the to the water phase, under continuous mechanical stirring, and the $\mathrm{O} / \mathrm{W}$ emulsions occurred spontaneously. The produced $\mathrm{O} / \mathrm{W}$ emulsions were left under mechanical stirring for $1 \mathrm{~h}$ at room temperature and after which phenoxyethanol and ethylhexylglycerin preservatives were added in each cream. A control emulsion (blank) without the presence of kraft LGN, MWCNTs and GO nanoadditives was also prepared according to the procedure mentioned above.

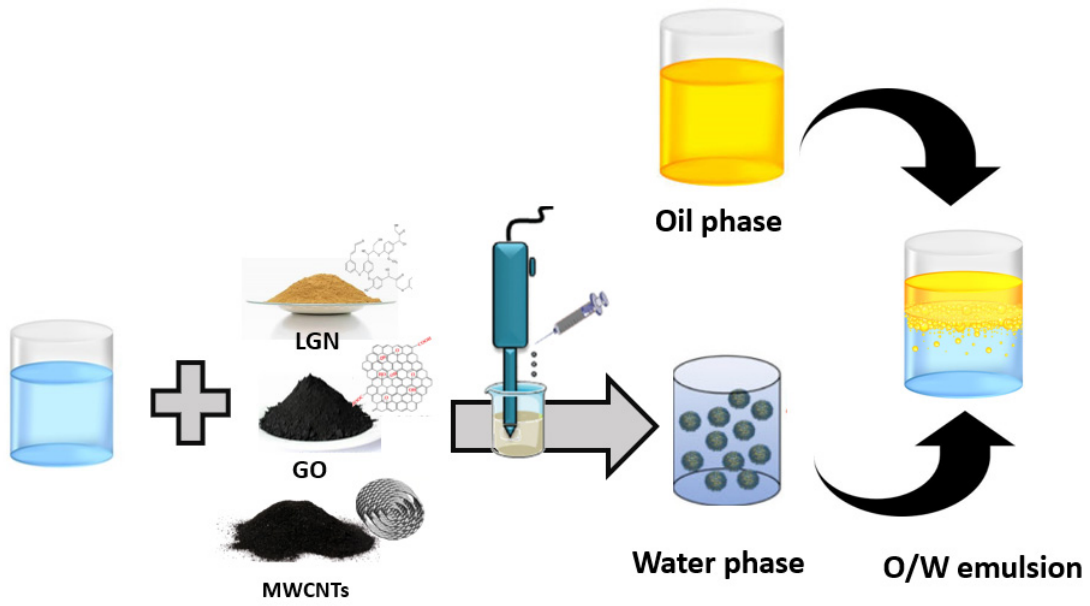

Figure 2. Experimental procedure of fabricated $\mathrm{O} / \mathrm{W}$ emulsions.

\subsection{Characterization of the Emulsions}

\subsubsection{Emulsion Stability}

The emulsion stability was assessed measuring $\mathrm{pH}$ and viscosity after 1, 7, 14, 30, 60 and 90 days since the synthesis of the emulsions. $\mathrm{pH}$ measurements were performed by dipping a pH sensor (Microprocessor, WTW, pH 535, Gemini BV, Apeldoorn, The Netherlands) into produced emulsions. The viscosity values were evaluated under 50 and 100 RPM utilizing R3 spindle of a Visco Star Plus viscometer. For all samples, experiments were performed in triplicate and results are presented in mean values. 
Table 1. Ingredients of the prepared $\mathrm{O} / \mathrm{W}$ emulsions.

\begin{tabular}{|c|c|c|c|c|c|c|c|c|c|c|}
\hline Sample Name & Blank & $\begin{array}{l}0.5 \% \\
\text { LGN }\end{array}$ & $\begin{array}{l}1 \% \\
\text { LGN }\end{array}$ & $\begin{array}{l}2 \% \\
\text { LGN }\end{array}$ & $\begin{array}{l}0.5 \% \\
\text { GO }\end{array}$ & $\begin{array}{l}1 \% \\
\text { GO }\end{array}$ & $\begin{array}{l}2 \% \\
\text { GO }\end{array}$ & $\begin{array}{c}0.5 \% \\
\text { MWCNTs }\end{array}$ & $\begin{array}{c}1 \% \\
\text { MWCNTs }\end{array}$ & $\begin{array}{c}2 \% \\
\text { MWCNTs }\end{array}$ \\
\hline Ingredients (\%) & \multicolumn{10}{|c|}{ Water phase } \\
\hline Water & 67 & 66.5 & 66 & 65 & 66. & 66 & 65 & 66.5 & 66 & 65 \\
\hline Glycerin & 3.5 & 3.5 & 3.5 & 3.5 & 3.5 & 3.5 & 3.5 & 3.5 & 3.5 & 3.5 \\
\hline Citric acid & 0.5 & 0.5 & 0.5 & 0.5 & 0.5 & 0.5 & 0.5 & 0.5 & 0.5 & 0.5 \\
\hline Xanthan gum & 1 & 1 & 1 & 1 & 1 & 1 & 1 & 1 & 1 & 1 \\
\hline Kraft LGN & & 0.5 & 1 & 2 & & & & & & \\
\hline GO & & & & & 0.5 & 1 & 2 & & & \\
\hline \multirow[t]{2}{*}{ MWCNTs } & & & & & & & & 0.5 & 1 & 2 \\
\hline & \multicolumn{10}{|c|}{ Oil phase } \\
\hline Olive oil & 13 & 13 & 13 & 13 & 13 & 13 & 13 & 13 & 13 & 13 \\
\hline Cetyl alcohol & 2 & 2 & 2 & 2 & 2 & 2 & 2 & 2 & 2 & 2 \\
\hline Cetearyl alcohol & 2 & 2 & 2 & 2 & 2 & 2 & 2 & 2 & 2 & 2 \\
\hline Stearic acid & 2 & 2 & 2 & 2 & 2 & 2 & 2 & 2 & 2 & 2 \\
\hline Shea butter & 2 & 2 & 2 & 2 & 2 & 2 & 2 & 2 & 2 & 2 \\
\hline Beeswax & 2 & 2 & 2 & 2 & 2 & 2 & 2 & 2 & 2 & 2 \\
\hline Polysorbate 60 & 2 & 2 & 2 & 2 & 2 & 2 & 2 & 2 & 2 & 2 \\
\hline
\end{tabular}

\subsubsection{Centrifugal Tests}

Centrifugal tests of produced emulsions were determined after preparation as well as after 1, 3 and 20 days of storage. $3 \mathrm{~g}$ of each sample was placed in centrifugal tubes and then centrifugated at $4000 \mathrm{rpm}$ and $25^{\circ} \mathrm{C}$ for $15 \mathrm{~min}$.

\subsubsection{Antioxidant Activity}

Tests measuring the antioxidant capability of the samples was determined using the 2,2-Diphenyil-1-picrylhydrazyl (DPPH) method, developed according to Blois in 1958 [44] $1 \mathrm{~mL}$ of each emulsion dispersed in $\mathrm{EtOH}(1 \% v / v)$ was added to $3 \mathrm{~mL}$ of a $5 \times 10^{-3} \mathrm{mg} / \mathrm{mL}$ ethanol DPPH solution. The reference sample consisted of $1 \mathrm{mLEtOH}$ and $3 \mathrm{~mL}$ of the DPPH/EtOH solution. The samples were then sonicated, and their absorbance was recorded after $30 \mathrm{~min}$ with the aid of a UV-Vis spectrometer (UV Probe 1650, Shimadzu, Tokyo, Japan) at $517 \mathrm{~nm}$. The Equation (1) proposed by Brand et al. was used to determine the free radical scavenging activity of the samples [45]:

$$
\text { Free radical scavenging activity }(\%)=\frac{\text { Absorbance of control }- \text { Absorbance of extracts }}{\text { Absorbance of control }} \times 100
$$

For all samples, experiments were performed in triplicate and results are presented in mean values.

\subsubsection{SPF Determination}

For the assessment of sun protection factor, the diluted solution transmittance technique was employed [46]. $1 \mathrm{~g}$ of each sample was transferred to a $100 \mathrm{~mL}$ volumetric flask, and then sonicated until complete homogenization, diluted to volume with ethanol, mixed for $5 \mathrm{~min}$ and filtered through Whatman filters. $2 \mathrm{~mL}$ of each sample was transferred to a $10 \mathrm{~mL}$ volumetric flask and diluted with ethanol. The absorption values of the samples were obtained in the range of 290-320 nm (every $5 \mathrm{~nm}$ ) using a UV-Vis spectrophotometer (Shimadzu, Tokyo, Japan) while experiments for each sample were performed in trip- 
licate. Equation (2) proposed by Mansur was used to determine the SPF values of the formulations [47]:

$$
\text { SPF in vitro }=\mathrm{CF} \times \sum_{290}^{320} \mathrm{EE}(\lambda) \times \mathrm{I}(\lambda) \times \operatorname{abs}(\lambda)
$$

where $\mathrm{CF}=10$ (correction factor), $\mathrm{EE}(\lambda)=$ erythemogenic effect of radiation at wavelength $\lambda, \mathrm{I}(\lambda)=$ intensity of solar light at wavelength $\lambda$, and $\operatorname{abs}(\lambda)=$ absorbance of sample at wavelength $\lambda$. The values for the term "EE $\times \mathrm{I}^{\prime}$ " are constants, which were determined by Sayre et al. [47]. For all samples, experiments were performed in triplicate and results are presented in mean values.

\subsubsection{UV Irradiation}

Emulsions ( $0.5 \mathrm{~g}$ of each sample), placed at an aluminum foil (Figure 3), were left under UV irradiation (chamber BS-09) at $280 \mathrm{~nm}$ at constant temperature $\left(25^{\circ} \mathrm{C}\right)$ and relative humidity $(50 \%)$ for several hours. The irradiation intensity samples were exposed at a distance of $25 \mathrm{~cm}$ from the lamp, at an irradiated area of $35 \mathrm{~cm} \times 45 \mathrm{~cm}$. After exposure the creams were removed from the chamber (after 24 and $72 \mathrm{~h}$ of UV exposure) and the effect of UV exposure was evaluated by using spectrophotometer HUNTERLAB (Washington, VA, USA) MiniScan XE Plus. All measurements were performed in triplicates and an average value was selected.

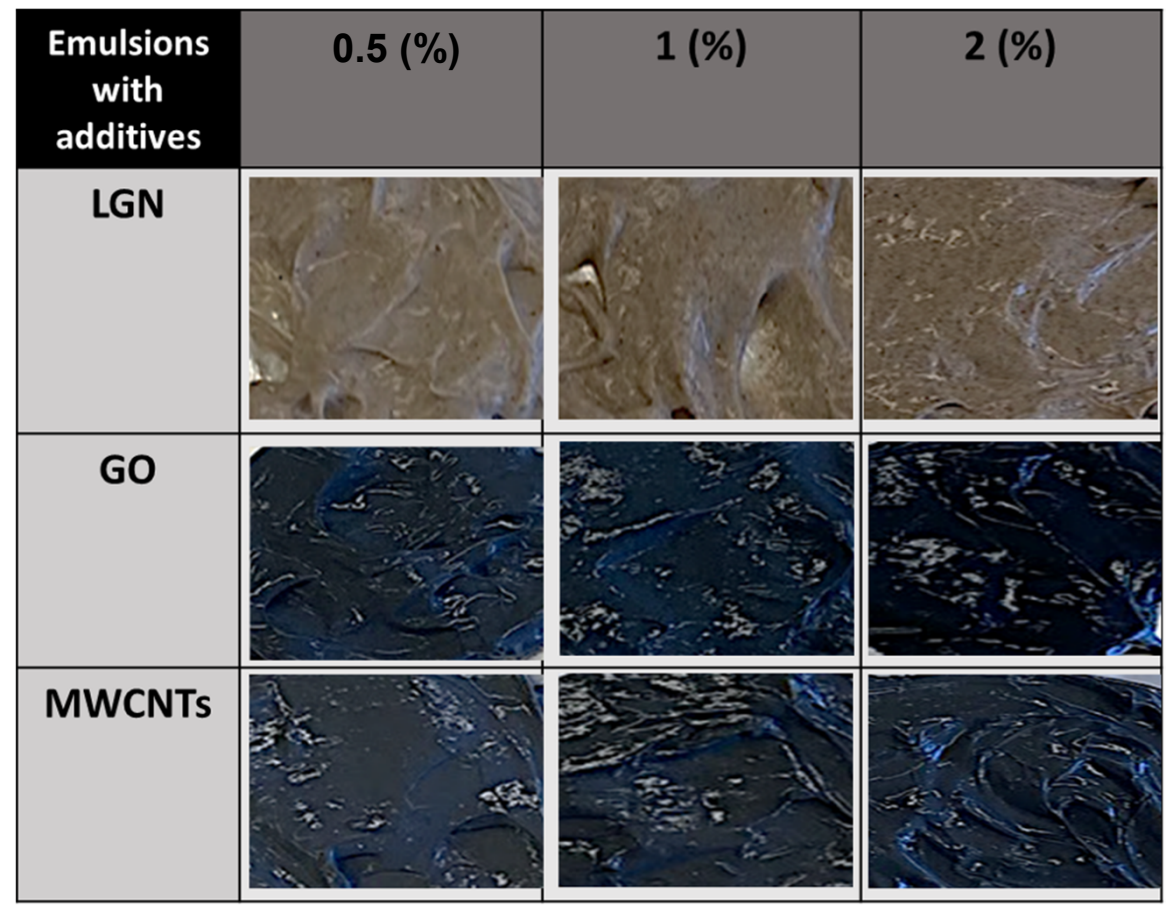

Figure 3. Samples of prepared $\mathrm{O} / \mathrm{W}$ emulsions on aluminum foil before UV irradiation.

\section{Results and Discussion}

\subsection{Stability of the Prepared Emulsions}

Emulsion stability is associated either with the decay or the persistence of the dispersed system under specific conditions. Viscosity constitutes an index of the inner stability and thus greatly affects the appealing of the final product to the consumers. Flaws in viscosity during storage may cause various failings, not only regarding aesthetic appearance (liquefaction) but also in the essential features of the final product, such as the sun protection capability of the emulsion and potentially provoke phase separation and liquefaction. The key mechanism describing the stabilization of the emulsion is the irreversible adsorption of solid particles at the oil-water interface, providing a steric barrier against droplet 
coalescence and Ostwald ripening. The above-described case mostly applies when solid particles have a good wettability for the oil phase, contributing to the formation of a dense layer of adsorbed particles around the droplets. Under this condition, the energy barrier against the coalescence of oil droplets corresponds to the energy involved to expel the particles from the interface. Other factors benefiting the stabilization process include electrostatic repulsion induced by charged particles, or the setup of a three-dimensional network in the continuous phase induced by the solid particles that entrap the dispersed droplets and restrain their mobility [9].

The only complete method to determine viscosity stability is to count the number of drops in the system and to assess how it variates as time elapses. However, this is impracticable due to the fact that the majority of measurement techniques require dilution and thus modification of the emulsion [2,48]. Figure 4 a shows the viscosity values in $\mathrm{cP}$ for all the prepared emulsions at 100 RPM, while Figure $4 \mathrm{~b}$ shows the viscosity values at 50 RPM. Concerning the blank emulsion, an advanced still very low decrease of viscosities during storage, credited to the needed time of the emulsions to coagulate, is manifested. The adding of bioactives leads to a reduction of the emulsion viscosities during the first 20 days in all cases, as was expected, since these are solid units. After this period, all of the prepared emulsions manifested increased viscosity, attributed to the hydration of the added particles, resulting in the stability of the final emulsions. The above phenomenon is highly desirable for sunscreens since higher viscosity values can contribute to great photoprotection ability, since the consumer often tends to apply a thicker layer of the product, leading to a more effective film (higher SPF). At both rotation speeds, a correlation is observed between the ratio of added substance with the increase of viscosity values, which is due to a tighter packing and increased inter-drop interactions, while emulsion containing $2 \% w / v$ MWCNTs is stabilized in highest viscosity values. In addition, after 60 days we observed a decrease in the viscosity of emulsions containing lignin, possibly attributed to phase separation.

The $\mathrm{pH}$ values of a vigorous human skin vary between $4.5-6$ range. Subsequently, the $\mathrm{pH}$ of the prepared $\mathrm{O} / \mathrm{W}$ emulsions should vary between this region. Various skin disorders may occur from extreme $\mathrm{pH}$ values, thus the examination of the $\mathrm{pH}$ values of the prepared samples is of great significance [49]. $\mathrm{pH}$ values exhibited in Figure 5 for up to 90 days indicate the good $\mathrm{pH}$ stability of all prepared emulsions since their $\mathrm{pH}$ values are very close to the blank sample. In almost all cases, the addition of LGN, MWCNTs and GO at different ratios ( 0.5 up to $2 \% \mathrm{w} / \mathrm{v})$, does not appear to have any effect on the $\mathrm{pH}$ values of the prepared emulsions. This was anticipated since the added portions were too low. A key factor contributing to the stability of the emulsion is the constant $\mathrm{pH}$ values observed over a period of time. Consequently, from the obtained measurements it can be established that all emulsions are likely to have steady $\mathrm{pH}$ values during storage, with no significant changes, thus constituting them appropriate for cosmetic dermal applications.

\subsection{Sun Protection}

Table 2 and Figure 6 present the SPF values of the prepared emulsions along with the blank one. The incorporation of lignin, graphene oxide and multi-walled carbon nanotubes into emulsions was able to produce a photoprotective formulation. All the emulsions exhibit improved SPF values compared to the blank sample, presenting increase of SPF index with increasing of the additives content. Specifically, the emulsion with $0.5 \%$ and $1 \%$ LGN presented SPF 6.48 and 7.4 respectively while the emulsion with $2 \%$ LGN exhibited a sharp increase with SPF 21.24 which is justified by the double lignin content. Emulsion with 0.5 and $1 \%$ graphene oxide with SPF 8.43 and 9.7 respectively showed similar behavior to the lignin emulsions. However, the emulsion with $2 \%$ graphene oxide presented low increase with SPF 11.29, which may be down to insufficient solubility of the additives in the emulsion [50]. All emulsions with multi-walled carbon nanotubes presented considerably high index SPF. Emulsions with 0.5 and 1\% multi-walled carbon nanotubes exhibited 
9.45 and 15.62 SPF values respectively while the emulsions with $2 \%$ multi-walled carbon nanotubes illustrated rapid increase with SPF 31.82.

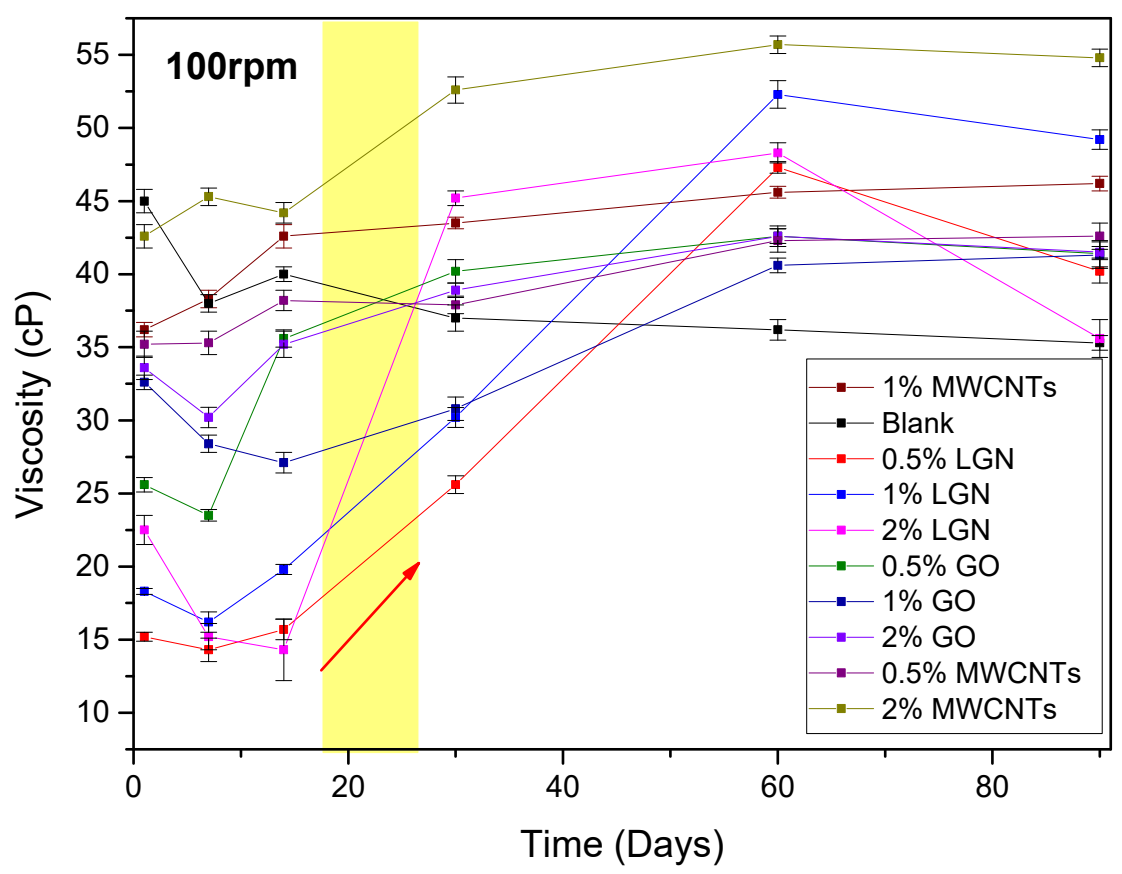

(a)

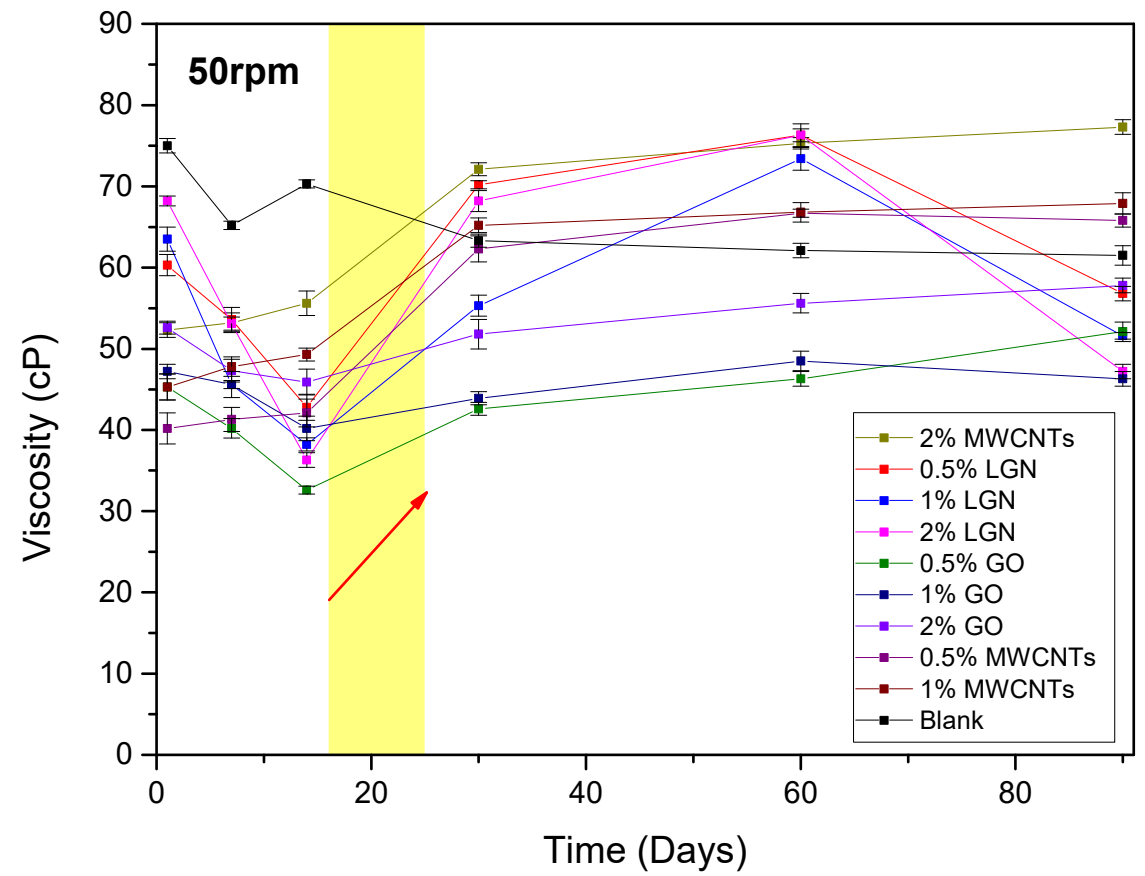

(b)

Figure 4. (a) Viscosity values at 100 RPM of the prepared emulsions during 90 days of storage. (b) Viscosity values at 50 RPM of the prepared emulsions during 90 days of storage. 


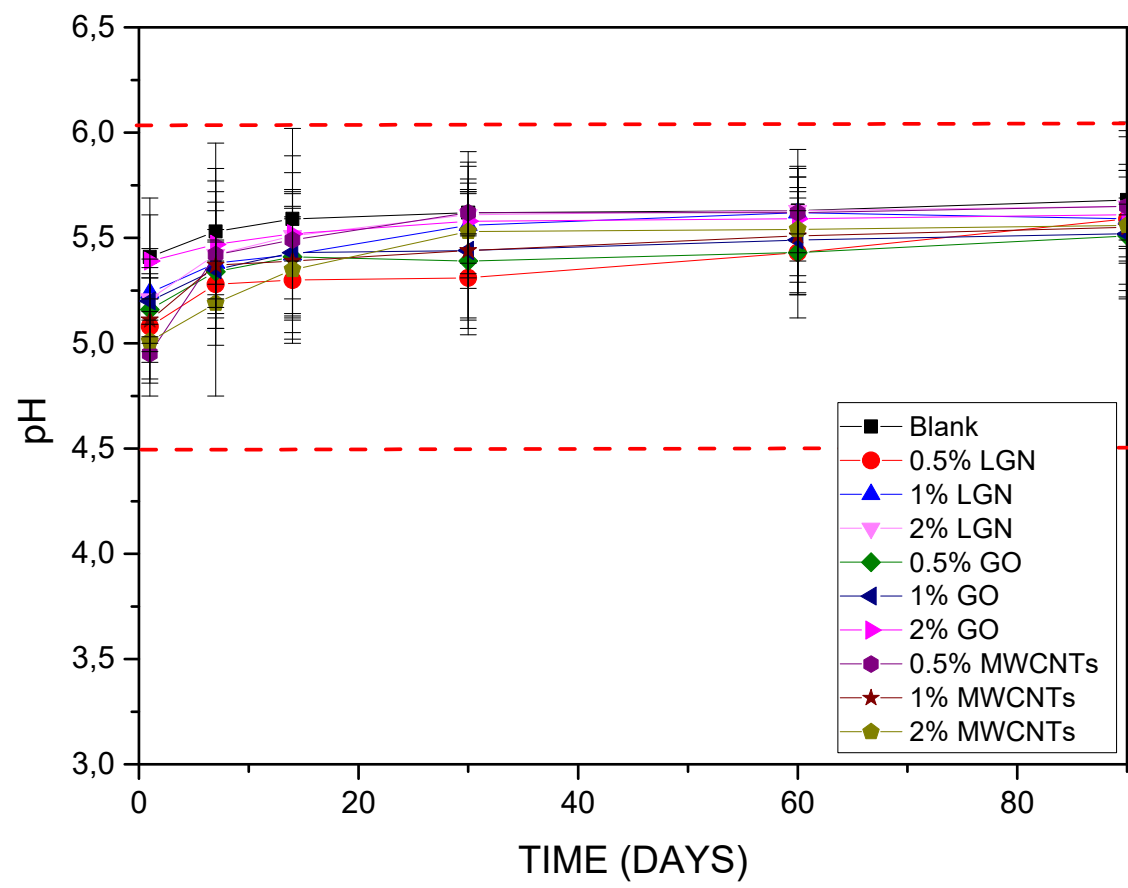

Figure 5. $\mathrm{pH}$ values obtained from the prepared emulsions during storage stability tests.

Table 2. SPF values of the prepared emulsions.

\begin{tabular}{cc}
\hline Sample & SPF \\
\hline Blank & $1.01 \pm 0.4$ \\
$0.5 \%$ LGN & $6.48 \pm 0.5$ \\
\% LGN $\%$ LN & $7.4 \pm 0.6$ \\
$0.5 \%$ GO & $21.2 \pm 0.5$ \\
$1 \%$ GO & $8.43 \pm 0.4$ \\
$2 \%$ GO & $9.7 \pm 0.6$ \\
$0.5 \%$ MWCNTs & $11.2 \pm 0.7$ \\
$1 \%$ MWCNTs & $9.45 \pm 0.8$ \\
$2 \%$ MWCNTs & $15.6 \pm 0.5$ \\
\hline
\end{tabular}

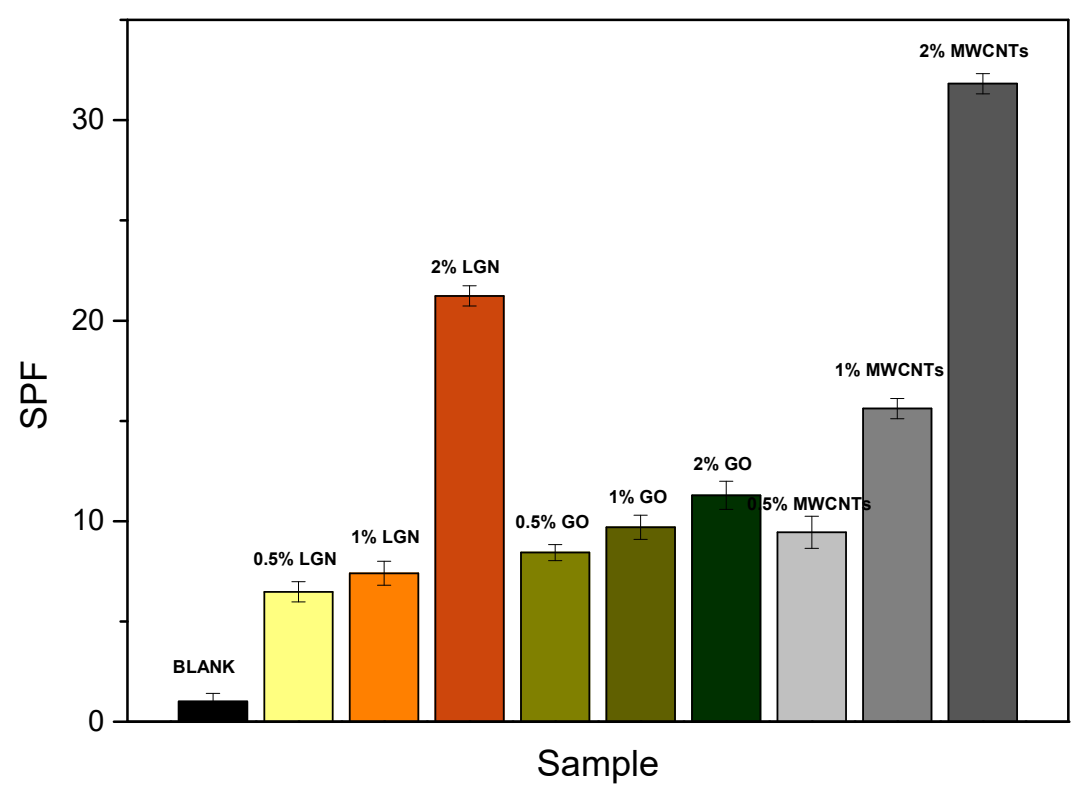

Figure 6. Sun protection ability of the emulsions. 


\subsection{Centrifugal Tests}

Centrifugation tests confirmed the stability of the prepared $\mathrm{O} / \mathrm{W}$ emulsions. A phenomenon commonly exhibited in commercially available products is the gravitational separation of emulsions. Images in Figure 7 confirm that no phase separation was observed at any sample during the 20 first days of centrifugation study. This finding is in total agreement with Smaoui et al. and is ascribed to accurate homogenization speed of the emulsions [51].

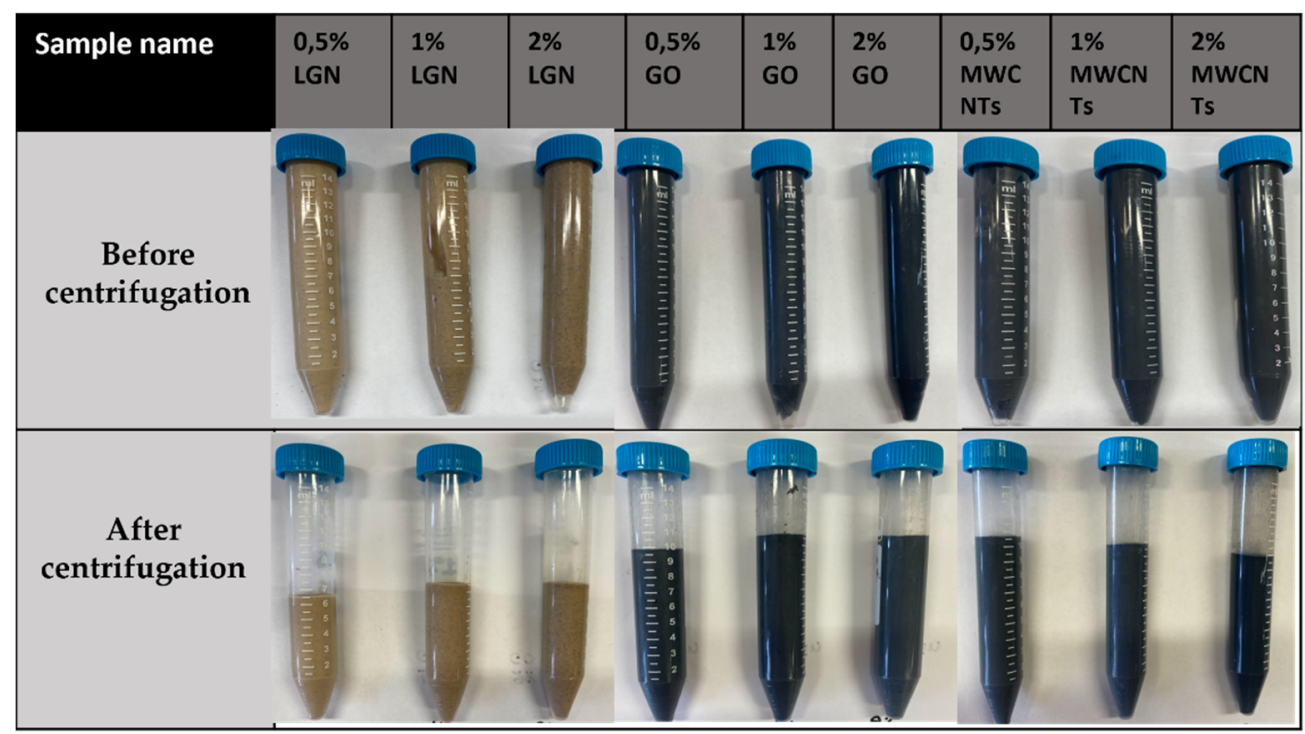

Figure 7. Images of $\mathrm{O} / \mathrm{W}$ emulsions before and after centrifugation at $4000 \mathrm{RPM}, 25{ }^{\circ} \mathrm{C}$ for $15 \mathrm{~min}$. No phase separation is witnessed at any of the emulsions.

\subsection{Antioxidant Properties}

Emulsions with LGN were found to exhibit great antioxidant activities (Figure 8) unlike to emulsions with GO and MWCNTs, which did not show any antioxidant activity. The antioxidant ability of lignin emulsions is attributed to the presence of free phenolic hydroxyl groups in the lignin structure, which act as radical scavengers (Ar-OH, MeO-Ar$\left.\mathrm{OH},(\mathrm{MeO})_{2}-\mathrm{Ar}-\mathrm{OH}\right)[52,53]$. The radical scavenging ability of phenolic groups depends not only on the ability to form but also on the stability of phenoxyl radical. Methoxyl groups in lignin structure at ortho position stabilize phenoxyl radicals by resonance as well as preventing them from propagation (Figure 9). Conjugated double bonds increase the stabilization is through extended delocalization [54]. As was expected, results showed that the antioxidant ability was increased by increasing lignin amount due to higher content of phenolic hydroxyl groups. The relatively high antioxidant activity of lignin suggested that it could be used as potential antioxidant of emulsions.

Despite its phenolic nature, the high safety levels of different concentrations of lignin in emulsions make it ideal additive for cosmetic products [55]. Specifically, cell viability results for emulsions with $0.005-0.5 \mathrm{wt} \%$ concentration of lignin $\mathrm{w}$ greater than $80 \%$ [56]. Excellent non-cytotoxic activities have been also reported for materials containing $1 \mathrm{wt} \%$ lignin [22]. Similarly, emulsions with $3 \mathrm{wt} \%$ content of lignin did not show any evidence of toxic effects for fibroblast after $72 \mathrm{~h}$ [57]. These results demonstrate that despite the phenolic nature of lignin, it can be used as a material for applications in cosmetics. 


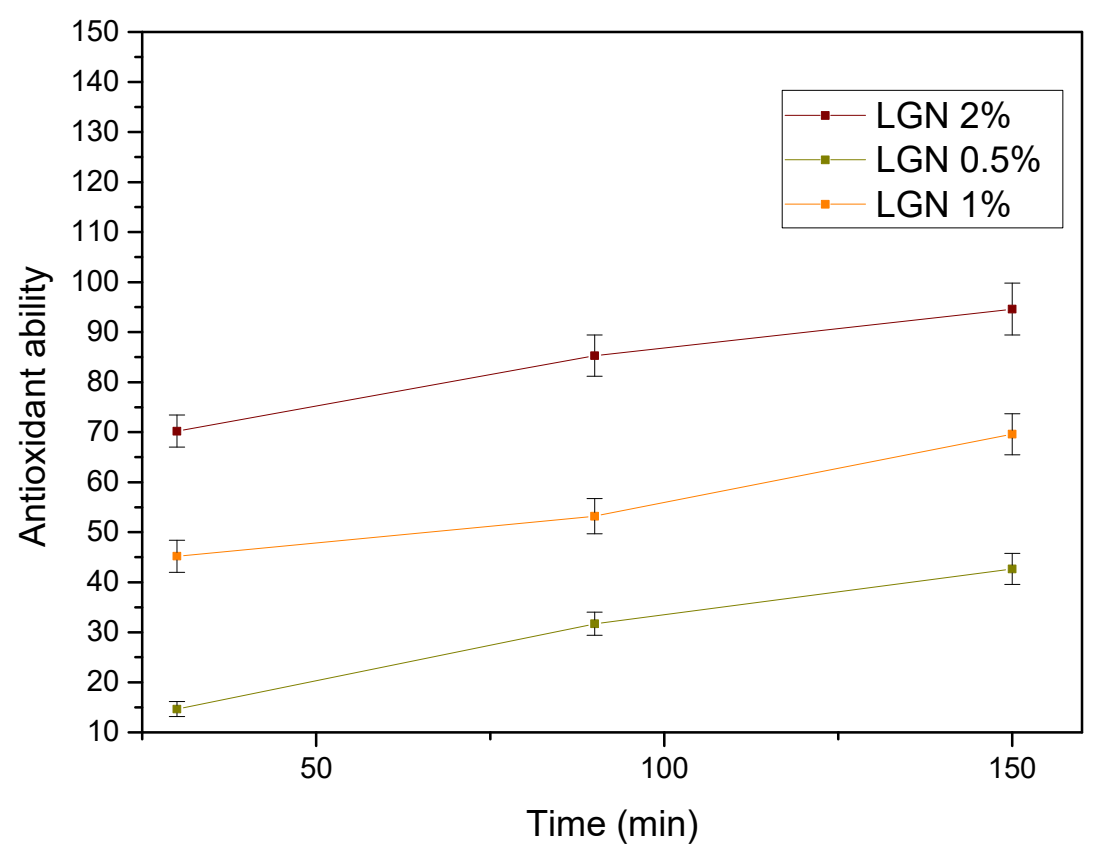

Figure 8. Antioxidant ability of emulsions during the first $2.5 \mathrm{~h}$.

$\mathrm{DPPH}^{\bullet}+\mathrm{AH} \rightarrow \mathrm{DPPH}-\mathrm{H}+\mathrm{A}^{\bullet}$

$\mathrm{DPPH}^{\bullet}$ :<smiles>O=[N+]([O-])c1cc([N+](=O)[O-])c(NN(c2ccccc2)c2ccccc2)c([N+](=O)[O-])c1</smiles>

Antioxidant $(\mathrm{AH})$ : Lignin<smiles>COc1cccc(/C=C/CO)c1O</smiles><smiles>COc1cc(O)cc(/C=C/CO)c1</smiles><smiles>COc1cc(/C=C/CO)cc(O)c1O</smiles><smiles></smiles><smiles>CC(C)(C)C</smiles><smiles>C/C=C/C1C=CC(=O)C(OC)=C1</smiles><smiles>COC(=O)/C=C\C=C\CCO</smiles>

Figure 9. Trapping and stabilization of radicals by lignin.

\subsection{UV Stability}

UV irradiation effects on emulsions were determined in terms of color evaluation by means of the changes of Commission Internationale de 1'Eclairage (CIE) Lab color components $L^{*} a^{*} b^{*} C^{*} h$. Five-dimensional color space measurement system in which the $\mathrm{L}^{*}$ axis measures luminosity or lightness ranging from 0 (black) to 100 (white), the $\mathrm{a}^{*}$ coordinate measures redness $(a>0)$ or greenness $(a<0)$, and the $b^{*}$ coordinate measures yellowness $(b>0)$ or blueness $(b<0), C^{*}$-chroma and $H^{*}$-hue angle $[58,59]$. Creams prepared with lignin as active ingredient at application levels of $0.5,1$ and $2 \% w / v$ show progressively increasing brown coloration from pale brown (higher L value) to dark brown (lower L value), which can be attributed to the higher level of lignin employed in the preparation of the creams. Additionally, by increasing the lignin concentration, the creams are becoming reddish as this can be seen from the higher values recorded, which again can be attributed to the higher application level of the lignin employed (Table 3). The colour stability of the lignin creams after 24 and $72 \mathrm{~h}$ of exposure to UV radiation is very stable as this can be seen from Table 3 with all the values of colour coordinates remaining relatively stable and very close to the same values of non-exposed samples. Creams prepared with 
MWCNTs as the active ingredient at application levels of $0.5,1$, and $2 \% w / v$ show grey black coloration with the cream prepared with $2 \%$ MWCNTs being the strongest colored (lower L value, Table 3). The colour stability of the creams prepared after UV exposure for 24 and $72 \mathrm{~h}$ remains excellent as it can be observed from Table 3 with all colour coordinates remaining very similar to the same values of non-exposed samples. Creams prepared with GO as active ingredient at application levels of $0.5,1$ and $2 \% w / v$ present dark grey coloration with the colour intensity remaining almost unaltered from the application level of the active ingredient (same L values, Table 3). This can be attributed to the fact that even the lower application level of $0.5 \%$ is enough to strongly colour the cream achieving a kind of colour saturation where further increase of the application level does not add to colour intensity. The colour stability of the creams prepared after UV exposure for 24 and $72 \mathrm{~h}$ is also excellent as this can be exemplified with the similar colour co-ordinates with the non-exposed samples.

Table 3. Color components of LGN, MWCNTs and GO containing emulsions with no UV exposure and after 24 and $72 \mathrm{~h}$ of UV irradiation.

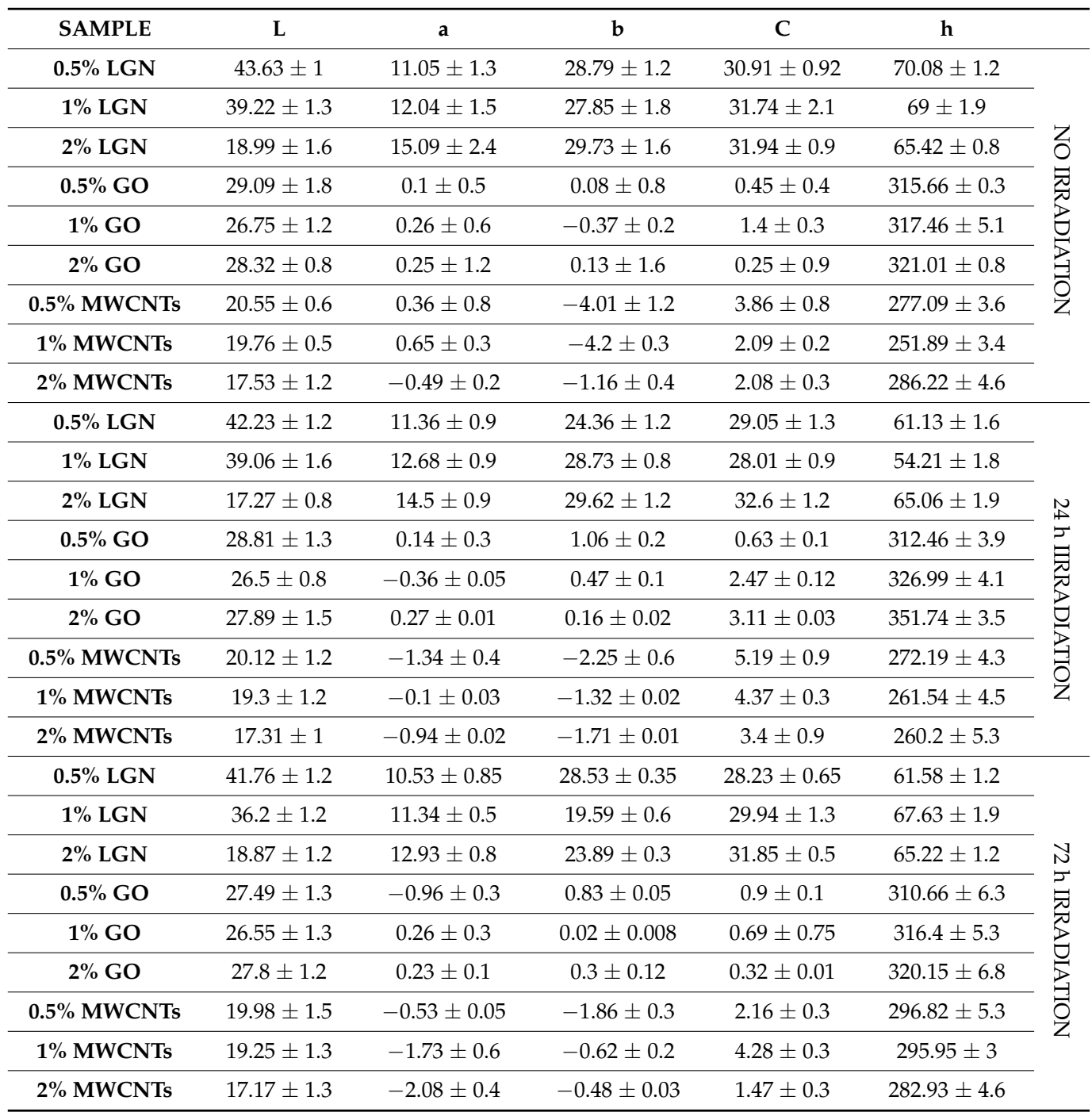

\section{Conclusions}

In the present study O/W emulsions containing LGN, MWCNTs and GO in ratios $0.5,1$ and $2 \% w / v$ were prepared. Stability tests conducted in this study indicate great viscosity and $\mathrm{pH}$ stability for up to 90 days storage at room temperature for all fabricated samples. Regarding the sun-protective ability, obtained SPF values varied between 6.48 and 
21.24. The highest SPF value was obtained by the emulsion containing $2 \% w / v$ MWCNTs, while the lowest by the $0.5 \% w / v$ LGN emulsion. The study of the antioxidant activity of the prepared emulsions, showed that only emulsions containing kraft lignin exhibited strong antioxidant activity associated with the existence of bioactive phenolic compounds in the structure of lignin. Finally, UV irradiation tests showed that all emulsions exhibit great UV stability after 24 and $72 \mathrm{~h}$ of exposure. The overall results exhibited in this study could further expand the usage of organic additives at cosmetic applications. Each additive offered excellent properties to the emulsions, so, in further research, it would be interesting to study the combination of LGN with GO and MWCNTs to synthesize emulsions with parallel enhanced antioxidant and UV protection properties. However, future cytotoxicity studies are required to fully evaluate the potential risk of produced emulsions to human health.

Author Contributions: N.D.B. and I.K. prepared emulsions, N.D.B., I.K. and S.L. characterized the emulsions, N.N., organized the experiments and N.D.B. and I.K. wrote the paper. All authors have read and agreed to the published version of the manuscript.

Funding: This research received no external funding.

Institutional Review Board Statement: Not applicable.

Informed Consent Statement: Not applicable.

Conflicts of Interest: The authors declare no conflict of interest.

\section{References}

1. Li, H.; Colantonio, S.; Dawson, A.; Lin, X.; Beecker, J. Sunscreen Application, Safety, and Sun Protection: The Evidence. J. Cutan. Med. Surg. 2019, 23, 357-369. [CrossRef]

2. Bikiaris, N.D.; Michailidou, G.; Lazaridou, M.; Christodoulou, E.; Gounari, E.; Ofrydopoulou, A.; Lambropoulou, D.A.; VergkiziNikolakaki, S.; Lykidou, S.; Nikolaidis, N. Innovative skin product emulsions with enhanced antioxidant, antimicrobial and UV protection properties containing nanoparticles of pure and modified Chitosan with encapsulated fresh pomegranate juice. Polymers 2020, 12, 1542. [CrossRef]

3. D'Orazio, J.; Jarrett, S.; Amaro-Ortiz, A.; Scott, T. UV radiation and the skin. Int. J. Mol. Sci. 2013, 14, 12222-12248. [CrossRef]

4. Martinez, R.M.; Fattori, V.; Saito, P.; Melo, C.B.P.; Borghi, S.M.; Pinto, I.C.; Bussmann, A.J.C.; Baracat, M.M.; Georgetti, S.R.; Verri, W.A.; et al. Lipoxin A4 inhibits UV radiation-induced skin inflammation and oxidative stress in mice. J. Dermatol. Sci. 2018, 91, 164-174. [CrossRef]

5. Ntohogian, S.; Gavriliadou, V.; Christodoulou, E.; Nanaki, S.; Lykidou, S.; Naidis, P.; Mischopoulou, L.; Barmpalexis, P.; Nikolaidis, N.; Bikiaris, D.N. Chitosan nanoparticles with encapsulated natural and Uf-purified annatto and saffron for the preparation of UV protective cosmetic emulsions. Molecules 2018, 23, 2107. [CrossRef]

6. Kowalska, M.; Ziomek, M.; Zbikowska, A. Stability of cosmetic emulsion containing different amount of hemp oil. Int. J. Cosmet. Sci. 2015, 37, 408-416. [CrossRef]

7. Venkataramani, D.; Tsulaia, A.; Amin, S. Fundamentals and applications of particle stabilized emulsions in cosmetic formulations. Adv. Colloid Interface Sci. 2020, 283, 102234. [CrossRef]

8. Stiller, S.; Gers-Barlag, H.; Lergenmueller, M.; Pflücker, F.; Schulz, J.; Wittern, K.P.; Daniels, R. Investigation of the stability in emulsions stabilized with different surface modified titanium dioxides. Colloids Surf. A Physicochem. Eng. Asp. 2004, 232, 261-267. [CrossRef]

9. Ben Cheikh, F.; Ben Mabrouk, A.; Magnin, A.; Putaux, J.L.; Boufi, S. Chitin nanocrystals as Pickering stabilizer for O/W emulsions: Effect of the oil chemical structure on the emulsion properties. Colloids Surf. B Biointerfaces 2021, 200, 111604. [CrossRef]

10. Dupont, H.; Laurichesse, E.; Héroguez, V.; Schmitt, V. Green Hydrophilic Capsules from Cellulose Nanocrystal-Stabilized Pickering Emulsion Polymerization: Morphology Control and Spongelike Behavior. Biomacromolecules 2021, 22, 3497-3509. [CrossRef]

11. Amar Feldbaum, R.; Yaakov, N.; Ananth Mani, K.; Yossef, E.; Metbeev, S.; Zelinger, E.; Belausov, E.; Koltai, H.; Ment, D.; Mechrez, G. Single cell encapsulation in a Pickering emulsion stabilized by $\mathrm{TiO}_{2}$ nanoparticles provides protection against UV radiation for a biopesticide. Colloids Surf. B Biointerfaces 2021, 206, 111958. [CrossRef]

12. Gao, D.; Wong, R.C.H.; Wang, Y.; Guo, X.; Yang, Z.; Lo, P.C. Shifting the absorption to the near-infrared region and inducing a strong photothermal effect by encapsulating zinc(II) phthalocyanine in poly(lactic-co-glycolic acid)-hyaluronic acid nanoparticles. Acta Biomater. 2020, 116, 329-343. [CrossRef]

13. Lin, Q.; Xu Xu, R.H.J.; Yang, N.; Karim, A.A.; Loh, X.J.; Zhang, K. UV Protection and Antioxidant Activity of Nanodiamonds and Fullerenes for Sunscreen Formulations. ACS Appl. Nano Mater. 2019, 2, 7604-7616. [CrossRef]

14. Shokri, J. Nanocosmetics: Benefits and risks. BioImpacts 2017, 7, 207-208. [CrossRef] 
15. Ajazzuddin, M.; Jeswani, G.; Jha, A.K. Nanocosmetics: Past, Present and Future Trends. Nanomedicine 2015, 5, 3-11. [CrossRef]

16. Holladay, R.J.; Moelle, W.; Mehta, D.; Roy, R.; Julian, H.J.; Brooks, M.G.M. Silver/Water, Silver Gels and Silver-Based Compositions: And Methods for Making and Using the Same. E.P. Patent EP1880213A4, 23 June 2010.

17. Lu, P.J.; Huang, S.C.; Chen, Y.P.; Chiueh, L.C.; Shih, D.Y.C. Analysis of titanium dioxide and zinc oxide nanoparticles in cosmetics. J. Food Drug Anal. 2015, 23, 587-594. [CrossRef]

18. Bilal, M.; Iqbal, H.M.N. New insights on unique features and role of nanostructured materials in cosmetics. Cosmetics 2020, 7, 24 . [CrossRef]

19. Vetrivel, R.; Navinselvakumar, C.; Samuel Ratna Kumar, P.S. Carbon nanotubes and its applications-A review. Int. J. Mech. Prod. Eng. Res. Dev. 2018, 8, 288-293.

20. Huang, X.; Kobos, R.K.; Xu, G. Hair Coloring and Cosmetic Compositions Comprising Carbon Nanotubes. U.S. Patent US7276088B2, 2 October 2007.

21. Ni, S.; Han, F.; Wang, W.; Han, D.; Bao, Y.; Han, D.; Wang, H.; Niu, L. Innovations upon antioxidant capacity evaluation for cosmetics: A photoelectrochemical sensor exploitation based on $\mathrm{N}$-doped graphene $/ \mathrm{TiO}_{2}$ nanocomposite. Sens. Actuators $B$ Chem. 2018, 259, 963-971. [CrossRef]

22. Sadeghifar, H.; Ragauskas, A. Lignin as a UV Light blocker-a review. Polymers 2020, 12, 1134. [CrossRef]

23. Paulsson, M.; Parkås, J. Light-Induced Yellowing of Lignocellulosic Pulps-Mechanisms and Preventive Methods Introduction and Scope of the Review. BioResources 2012, 7, 5995-6040. [CrossRef]

24. Argyropoulos, D.S.; Sun, Y. Photochemically induced solid-state degradation, condensation and rearrangement reactions in lignin model compounds and milled wood lignin. Photochem. Photobiol. 1996, 64, 510-517. [CrossRef]

25. Amrita, M.; Kamesh, B.; Revuru, R.S.; Venkataramana, V.S.N. Tribological Behavior of Graphene-Dispersed Emulsifier Cutting Fluid. J. Inst. Eng. Ser. C 2021, 102, 1091-1097. [CrossRef]

26. Murali, R.; Meindl, J.D. What is graphene? ACM SIGDA Newsl. 2009, 39, 1. [CrossRef]

27. Tarcan, R.; Todor-Boer, O.; Petrovai, I.; Leordean, C.; Astilean, S.; Botiz, I. Reduced graphene oxide today. J. Mater. Chem. C 2020, 8, 1198-1224. [CrossRef]

28. McCoy, T.M.; Pottage, M.J.; Tabor, R.F. Graphene oxide-stabilized oil-in-water emulsions: PH-controlled dispersion and flocculation. J. Phys. Chem. C 2014, 118, 4529-4535. [CrossRef]

29. Tang, X.; Tian, M.; Qu, L.; Zhu, S.; Guo, X.; Han, G.; Sun, K.; Hu, X.; Wang, Y.; Xu, X. Functionalization of cotton fabric with graphene oxide nanosheet and polyaniline for conductive and UV blocking properties. Synth. Met. 2015, 202, 82-88. [CrossRef]

30. Alloy, M.M.; Roberts, A.P. Effects of suspended multi-walled carbon nanotubes on daphnid growth and reproduction. Ecotoxicol. Environ. Saf. 2011, 74, 1839-1843. [CrossRef]

31. Briggs, N.; Raman, A.K.Y.; Barrett, L.; Brown, C.; Li, B.; Leavitt, D.; Aichele, C.P.; Crossley, S. Stable pickering emulsions using multi-walled carbon nanotubes of varying wettability. Colloids Surf. A Physicochem. Eng. Asp. 2018, 537, 227-235. [CrossRef]

32. Bornaee, A.H.; Manteghian, M.; Rashidi, A.; Alaei, M.; Ershadi, M. Oil-in-water Pickering emulsions stabilized with functionalized multi-walled carbon nanotube/silica nanohybrids in the presence of high concentrations of cations in water. J. Ind. Eng. Chem. 2014, 20, 1720-1726. [CrossRef]

33. AfzaliTabar, M.; Alaei, M.; Ranjineh Khojasteh, R.; Motiee, F.; Rashidi, A.M. Preference of multi-walled carbon nanotube (MWCNT) to single-walled carbon nanotube (SWCNT) and activated carbon for preparing silica nanohybrid pickering emulsion for chemical enhanced oil recovery (C-EOR). J. Solid State Chem. 2017, 245, 164-173. [CrossRef]

34. Masalova, I.; Kharatyan, E.; Malkin, A.Y. Multi-Walled Carbon Nanotubes as a Cosurfactant for Highly Concentrated Emulsions. J. Dispers. Sci. Technol. 2013, 34, 1074-1078. [CrossRef]

35. Amini, A.; Zohoori, S.; Mirjalili, A.; Karimi, L.; Davodiroknabadi, A. Improvement in physical properties of paper fabric using multi-wall carbon nanotubes. J. Nanostruct. Chem. 2014, 4, 103. [CrossRef]

36. Visconti, P.; Primiceri, P.; Longo, D.; Strafella, L.; Carlucci, P.; Lomascolo, M.; Cretì, A.; Mele, G. Photo-ignition process of multiwall carbon nanotubes and ferrocene by continuous wave Xe lamp illumination. Beilstein J. Nanotechnol. 2017, 8, 134-144. [CrossRef]

37. Oh, W.K.; Yoon, H.; Jang, J. Size control of magnetic carbon nanoparticles for drug delivery. Biomaterials 2010, 31, 1342-1348. [CrossRef]

38. Im, J.S.; Bai, B.C.; Lee, Y.S. The effect of carbon nanotubes on drug delivery in an electro-sensitive transdermal drug delivery system. Biomaterials 2010, 31, 1414-1419. [CrossRef]

39. Wang, C.; Zhang, Z.; Chen, B.; Gu, L.; Li, Y.; Yu, S. Design and evaluation of galactosylated chitosan/graphene oxide nanoparticles as a drug delivery system. J. Colloid Interface Sci. 2018, 516, 332-341. [CrossRef]

40. Zhu, Y.; Li, W.; Li, Q.; Li, Y.; Li, Y.; Zhang, X.; Huang, Q. Effects of serum proteins on intracellular uptake and cytotoxicity of carbon nanoparticles. Carbon N. Y. 2009, 47, 1351-1358. [CrossRef]

41. Fiorito, S.; Serafino, A.; Andreola, F.; Togna, A.; Togna, G. Toxicity and biocompatibility of carbon nanoparticles. J. Nanosci. Nanotechnol. 2006, 6, 591-599. [CrossRef]

42. Raslan, A.; Saenz del Burgo, L.; Ciriza, J.; Luis Pedraz, J. Graphene oxide and reduced graphene oxide-based scaffolds in regenerative medicine. Int. J. Pharm. 2020, 580, 119226. [CrossRef]

43. Ali, M.H.; Rubel, R.I. A comparative review of Mg/CNTs and Al/CNTs composite to explore the prospect of bimetallic Mg$\mathrm{Al} / \mathrm{CNTs}$ composites. AIMS Mater. Sci. 2020, 7, 217-243. [CrossRef] 
44. Blois, M.S. Antioxidant determinations by the use of a stable free radical. Nature 1958, 181, 1199-1200. [CrossRef]

45. Brand-Williams, W.; Cuvelier, M.E.; Berset, C. Use of a free radical method to evaluate antioxidant activity. LWT-Food Sci. Technol. 1995, 28, 25-30. [CrossRef]

46. Laeliocattleya, R.A. The potential of methanol and ethyl acetate extracts of corn silk (Zea mays L.) as sunscreen. AIP Conf. Proc. 2019, 2099, 020012. [CrossRef]

47. Sayre, R.M.; Agin, P.P.; LeVee, G.J.; Marlowe, E. A Comparison of in Vivo and in Vitro Testing of Sunscreening Formulas. Photochem. Photobiol. 1979, 29, 559-566. [CrossRef]

48. Rojas, O.J.; Bullón, J.; Ysambertt, F.; Forgiarini, A.; Salager, J.L.; Argyropoulos, D.S. Lignins as emulsion stabilizers. ACS Symp. Ser. 2007, 954, 182-199. [CrossRef]

49. Slim Smaoui Cosmetic emulsion from virgin olive oil: Formulation and bio-physical evaluation. African J. Biotechnol. 2012, 11, 9664-9671. [CrossRef]

50. Song, W.; Wang, B.; Fan, L.; Ge, F.; Wang, C. Graphene oxide/waterborne polyurethane composites for fine pattern fabrication and ultrastrong ultraviolet protection cotton fabric via screen printing. Appl. Surf. Sci. 2019, 463, 403-411. [CrossRef]

51. Smaoui, S.; Ben Hlima, H.; Ben Chobba, I.; Kadri, A. Development and stability studies of sunscreen cream formulations containing three photo-protective filters. Arab. J. Chem. 2017, 10, S1216-S1222. [CrossRef]

52. Crouvisier-Urion, K.; Bodart, P.R.; Winckler, P.; Raya, J.; Gougeon, R.D.; Cayot, P.; Domenek, S.; Debeaufort, F.; Karbowiak, T Biobased Composite Films from Chitosan and Lignin: Antioxidant Activity Related to Structure and Moisture. ACS Sustain. Chem. Eng. 2016, 4, 6371-6381. [CrossRef]

53. Moreno, A.; Morsali, M.; Liu, J.; Sipponen, M.H. Access to tough and transparent nanocompositesviaPickering emulsion polymerization using biocatalytic hybrid lignin nanoparticles as functional surfactants. Green Chem. 2021, 23, 3001-3014. [CrossRef]

54. Kaur, R.; Uppal, S.K. Structural characterization and antioxidant activity of lignin from sugarcane bagasse. Colloid Polym. Sci. 2015, 293, 2585-2592. [CrossRef]

55. Figueiredo, P.; Lintinen, K.; Hirvonen, J.T.; Kostiainen, M.A.; Santos, H.A. Properties and chemical modifications of lignin: Towards lignin-based nanomaterials for biomedical applications. Prog. Mater. Sci. 2018, 93, 233-269. [CrossRef]

56. Czaikoski, A.; Gomes, A.; Kaufmann, K.C.; Liszbinski, R.B.; de Jesus, M.B.; da Cunha, R.L. Lignin derivatives stabilizing oil-in-water emulsions: Technological aspects, interfacial rheology and cytotoxicity. Ind. Crops Prod. 2020, 154, 112762. [CrossRef]

57. Quraishi, S.; Martins, M.; Barros, A.A.; Gurikov, P.; Raman, S.P.; Smirnova, I.; Duarte, A.R.C.; Reis, R.L. Novel non-cytotoxic alginate-lignin hybrid aerogels as scaffolds for tissue engineering. J. Supercrit. Fluids 2015, 105, 1-8. [CrossRef]

58. Šicklep, M.; Čandek-Potokar, M. Pork color measurement as affected by bloom time and measurement location. J. Muscle Foods 2007, 18, 78-87. [CrossRef]

59. Brooksbank, A.; Owens, B.M.; Phebus, J.G.; Blen, B.J.; Wasson, W. Surface sealant effect on the color stability of a composite resin following ultraviolet light artificial aging. Oper. Dent. 2019, 44, 322-330. [CrossRef] 